\title{
Socio-demographic correlates of quality of life in spinal cord injured patients
}

\author{
(iD) Abiodun Luqman Azeez ${ }^{1}$, (D) Adebisi I. Hammed ${ }^{2}$ \\ ${ }^{1}$ Department of Surgery, University of Benin, Benin-City, Nigeria. \\ ${ }^{2}$ Department of Physiotherapy, University of Benin Teaching Hospital, Benin City, Nigeria.
}

\begin{abstract}
Spinal cord injury (SCI) is one of the greatest calamities that can occur in humans' life. It brings about great challenges in the form of coping strategies as well as protocols of rehabilitation and characterized by high incidence of poor self-rated health. This study investigated socio-demographic correlates of healthrelated quality of life (HRQoL) among patients with SCI. Two separate self-rated questionnaires (the socioeconomic status questionnaire (SSQ) and generic SF-36 questionnaire) were administered to each of the participants to evaluate both socioeconomic statuses (SES) and HRQoL respectively. A total of 100 subjects with SCI of mechanical origin, aged 19-59 years participated in this study. Pearson product moment coefficient of correlation was used to analyze the relationship between HRQoL and socio-demographic parameters (age, gender, marital status, clinical characteristic of morbidity and SES) and however, one way analysis of variance (ANOVA) was used to analyze the differences in HRQoL across categories of SES. This study indicated that SES and clinical characteristic of morbidity (CCM) were the only variables correlating significantly $(p<0.05)$ with all the domains of HRQoL. In specific terms, the outcome suggested that low SES and complete SCI are associated with poor HRQoL components. However, age, gender and marital status were all found to associate poorly and insignificantly with most of the HRQoL domains ( $p>0.05$ ). The present study therefore submitted that in this population the most important determinants of HRQoL in SCI patients are SES and CCM. The implication of this finding is viewed in three different perspectives; first poor
\end{abstract}

SES could precipitate the onset of initial episode of SCI, second poor SES might lead to poor rehabilitation outcome and third long standing SCI can precipitate low SES.

Keywords. Health-related quality of life, socioeconomic status, spinal cord injury.

\section{Introduction}

Spinal cord injury (SCI) is an insult to the spinal cord resulting into reduction or loss of sensory, motor and/or autonomic dysfunctions below the level of injury due to trauma of neuronal elements of the spinal canal. It may be complete or incomplete, which could cause complications and changes in respiratory, thermal, circulatory and neuromotor functions as well as spasticity and pain (Pereira \& Araujo, 2006). SCI is possibly the most disruptive and traumatic event that can occur in humans' life. Infact SCI is one of the greatest calamities that can occur in anyone's life (Guttmann, 1973). It brings about great challenges in the form of coping strategies as well as protocols of rehabilitation. SCI may cause quadriplegia or paraplegia depending on the level of the injury which could affect the functions of limbs, trunk, pelvic organs, bladder and bowel, as well as sexual function. This loss of function could eventually cause great changes in life of the affected person making routine vocational,

Received: March 27, 2019 - Accepted: May 23, 2019 - Published: June 30, 2019

To cite this article: Azeez AL, Al Hammed. Socio-demographic correlates of quality of life in spinal cord injured patients. Turk J Kinesiol, 2019; 5(2): 92-101. 
social, sexual and recreational activities difficult. However, some individuals do recover partial capacity to perform certain basic activities of daily living through rehabilitation, while many activities would be permanently altered (e.g., assisted walking with support, micturition by supra-pubic pressure) (Somers, 2001). Quality of Life (QoL) is a broad concept that incorporates a person's perception of his or her physical health, psychological state, level of independence, social relationships, personal values and beliefs, and interaction with the environment (Chandra \& Ozturk, 2005). Health-Related Quality of Life (HRQoL) has received significant attention in medicine and allied health fields, which represents a subset of overall QoL and includes aspects of QoL that are directly related to humans' health and perhaps the overall aim of clinical intervention. Health professionals usually make quality of life judgments when making decisions about the care of patients, and the professional view of the expected QoL is often the key factor in determining whether effective treatment for a life-threatening condition will be given or withdrawn (Boakye et al., 2012). Therefore, it is imperative to assess the disability status and QoL in persons with SCI to characterize the natural history of the condition, assess treatment effectiveness, and develop an appropriate health and disability policy.

Moreover, morbidity and prognosis of clinical conditions such as SCI might be differently influenced by its gradients within specific regions of the world. Additionally, the overall impact of SCI which includes physical discomfort, functional limitation and emotional discomfort might characteristically affects sufferers' HRQoL. This is because health is defined by World Health Organization (2001) as a state of complete physical, mental and social well-being and not merely the absence of disease or infirmity. SCI could cause alterations in bodily functions including musculoskeletal, cardiovascular, neuromuscular and many others that affect QoL. Therefore, QoL measurement as well as the standard clinical and functional outcomes could be adopted to assess SCI outcomes (Boakye et al., 2012). According to Suttiwong et al. (2015), gender and marital status are important factors for QoL of patients with SCI. Past study reported that women with SCI exhibit a lack of vitality and vigor, and have a higher proportion of medical, social and psychological problems (Westgren \& Levi, 1998). In addition, studies have also reported that married individuals with SCI have less depression, greater psychological well-being and better QoL (Putzke et al., 2001; Erosa et al., 2014). A study in Canadian subjects with SCI (McColl et al., 2003) also found that married elderly couples were expected to have higher incomes, morale, life satisfaction, mental and physical health, and lower rates of institutionalization and high-risk health behaviours. In addition, age is a significant predictor of QoL among patients with SCI (Mittmann et al., 2014; Suttiwong et al., 2015), it appears to negatively affect QoL by deteriorating the level of health, because of multiple co-morbidities in the elderly, increasing fatigue and disability (Fekete et al., 2014). Equally, a higher financial capacity of patients with SCI creates more favorable conditions and provides for a better QoL (Blanes et al., 2007; Fekete et al., 2014). This could be attributed to increased comorbidity, complications and level of pain in patients of low socioeconomic status as well as low access to medical health care systems (Fekete et al., 2014). Also, Al-Jadid et al. (2004) revealed in their study that the health status and QoL of patients with SCI are affected by factors such as socioeconomic status (SES).

Several studies have been carried out to evaluate the association of socio-demographic characteristics and HRQoL among patients with SCI in developed countries. Some of these studies were of the view that physical domain, psychological domain, pain intensity, socio demographic factors such as ethnicity, SES, age, gender, marital status and education are significant correlates of HRQoL in patients with SCI (Suttiwong et al., 2015; Mittmann et al., 2014; Erosa et al., 2014; Fekete et al., 2014). However, little or no known researches have been undertaken in developing countries such as Nigeria 
regarding the association of socio-demographic variables with HRQoL among patients with SCI. This observed gap in knowledge and research efforts informed the need for the present study. This study therefore tried to establish the socioeconomic and demographic correlates of HRQoL of patients with SCI. This study could enhance the literature regarding $\mathrm{HRQ}$ oL of patients with $\mathrm{SCI}$, taking into cognizant the cultural and socioeconomic characteristics of different countries, and would also be helpful in comparison with other populations, for the scientific community and the treating medical professionals of patients with SCI.

\section{Methods}

The study population comprised of patients with SCI attending Neurosurgical Out-Patient Clinic of University of Benin Teaching Hospital (UBTH), Benin-City, Nigeria. Purposive sampling technique was used to select the participants. A total of 100 patients, age range 19 to 59 years were sampled out of the population of SCI patients attending the above mentioned tertiary health institution. The inclusion criteria were: 1) The SCI must be of mechanical origin, 2) The respondents should be within the age range of $19-59$ years.

All the respondents were recruited consecutively through their hospital files. Then the objectives and intricacies of the study were explained to them. The study protocol was explained to all of the respondents and each of the recruited sought their consent. The researcher administered the questionnaire face to face to the respondents, and the retrieval rate was $100 \%$.

HRQoL was assessed using SF36 questionnaire. The SF-36 is a 36 items tool that is structured into 8 domains, which are; physical functioning $(\mathrm{PF})$, role limitations due to physical health problems (RP), bodily pain $(\mathrm{BP})$, general health perceptions $(\mathrm{GH})$, vitality $(\mathrm{VT})$, social functioning $(\mathrm{SF})$, role limitation due to emotional problems (RE), and mental health $(\mathrm{MH})$. Responses vary from dichotomous (yes or no) to six point verbal rating scale (ordinal). All items in this tool were scored on a scale of0 to 100; with 100 representing the highest level of functioning possible. Aggregate scores were compiled as a percentage of the total points possible. The scores from those questions that address each domain of functional health status were aggregated and then averaged, to arrive at a final score within each of the 8 domains. The SF 36 reliability and validity have been determined in literatures (Omokhodion \& Sanya, 2003; Olusi et al., 1979).

SES of the respondents was measured using socioeconomic status questionnaire (SSQ). The SSQ was adopted from a previous study (Ware et al., 1995) as modified by Balogun et al. (1990) which has been validated by three different professionals; sport psychologist, sociologist and exercise physiologist and the total score of the items was calculated to be 60 which was used to categorize the respondents into groups of different SES (Low, middle and high) with ranges of $\leq 19,20-40$, and 41-60 respectively.

\section{Data Analysis}

The data obtained from the present study were analyzed using descriptive and inferential statistics. The socio-demographic characteristics of the respondents were summarized using frequencies and percentages (such characteristics include: age, gender, marital status, clinical characteristics of morbidity and SES) while mean and standard deviation were used to describe domains of HRQoL. Pearson product moment coefficient of correlation was used to analyze the relationship between HRQoL and socio-demographic parameters (age, gender, marital status, clinical characteristic of morbidity and SES) and however, one way analysis of variance (ANOVA) was used to analyze the differences in HRQoL across categories of SES. All statistical analyses were performed at 0.05 alpha levels using the Statistical Package for the Social Sciences (SPSS), version 22.0. 


\section{Results}

A total of one hundred (100) patients with SCI participated in this study, of which males constitutes larger part of the respondents ( $\mathrm{n}=78,78 \%)$. Most SCI patients that participated in this study were between the age of $19-29$ years $(n=55,55 \%)$, while the least were of the age of $50-59$ years $(n=7,7 \%)$, most respondents were single $(n=70,70 \%)$ and majority of the participants have incomplete SCI $(n=58,58 \%)$. These are all shown in table 1.

\section{Table 1}

Demographic variables and clinical characteristics of morbidity of participants.

\begin{tabular}{lc}
\hline Variables & $\mathrm{n}(\%)$ \\
\hline Age & $55(55)$ \\
$19-29$ & $28(28)$ \\
$30-39$ & $10(10)$ \\
$40-49$ & $7(7)$ \\
$50-59$ & \\
Gender & $78(78)$ \\
Male & $22(22)$ \\
Female & \\
Marital status & $70(70)$ \\
Single & $30(30)$ \\
Married & \\
Clinical characteristic of Morbidity & $58(58)$ \\
Incomplete & $42(42)$ \\
Complete & \\
\hline n frequency within a group or subgroup, $\%=$ percentage within a \\
group or subgroup.
\end{tabular}

Majority of the respondents were from middle socioeconomic class $(n=55,55 \%)$ while those from high socioeconomic class have the lowest percentage $(\mathrm{n}=20,20 \%)$ as reflected in Table 2.
Table 2

SES and HRQoL profile of respondents.

\begin{tabular}{|c|c|c|}
\hline Variables & $\mathrm{n}(\%)$ & $\mathrm{M} \pm \mathrm{SD}$ \\
\hline \multicolumn{3}{|l|}{ SES } \\
\hline Low & $25(25)$ & -- \\
\hline Middle & $55(55)$ & -- \\
\hline High & $20(20)$ & -- \\
\hline \multicolumn{3}{|l|}{ HRQoL } \\
\hline \multicolumn{2}{|l|}{$\mathrm{GH}$} & $57.25 \pm 14.83$ \\
\hline \multicolumn{2}{|l|}{$\mathrm{PF}$} & $52.45 \pm 21.62$ \\
\hline \multicolumn{2}{|l|}{$\mathrm{RP}$} & $54.55 \pm 17.91$ \\
\hline \multicolumn{2}{|l|}{ RE } & $54.60 \pm 15.07$ \\
\hline \multicolumn{2}{|l|}{ SF } & $57.35 \pm 14.74$ \\
\hline \multicolumn{2}{|l|}{$\mathrm{BP}$} & $58.91 \pm 16.24$ \\
\hline \multicolumn{2}{|l|}{ ME } & $59.65 \pm 13.89$ \\
\hline \multicolumn{2}{|l|}{ VT } & $58.15 \pm 15.47$ \\
\hline \multicolumn{3}{|c|}{$\begin{array}{l}\mathrm{n}=\text { frequency within a group or subgroup, } \%=\text { percentage within a } \\
\text { group or subgroup, } \mathrm{M} \pm \mathrm{SD}=\text { mean } \pm \text { standard deviation, } \\
\mathrm{SES}=\text { socioeconomic status, } \mathrm{HRQ} \mathrm{R}=\text { health related quality of life, GH- } \\
\text { general health perceptions, PF-physical functioning, RP -role } \\
\text { limitations due to physical health problems, RE- role limitation due to } \\
\text { emotional problems, SF-social functioning, BP-bodily pain, ME- } \\
\text { mental health, and VT- vitality. }\end{array}$} \\
\hline
\end{tabular}

Clinical characteristic of SCI morbidity (CCM) and SES were found to correlate proportionately and significantly with all domains of HRQoL $(p<0.05)$. This is an indication that patients with complete SCI and those with low SES are prone to have worse HRQoL. However, a disproportionate and insignificant relationship was found between marital status and domains of HRQoL, implying that subjects who are married have better HRQoL. Also, age was found to associate proportionately but insignificantly $(p>0.05)$ with all domains of HRQoL except the SF. This means that as the age increases, the HRQoL decreases and vice versa. It was equally seen from this study that an insignificant $(p>0.05)$ and disproportionate relationship exists in HRQoL domains (except GH and VT) across gender characteristics. All these are reflected in Table 3. 
Table 3

Correlations between health-related quality of life domains and sociodemographic variables.

\begin{tabular}{|c|c|c|c|c|c|c|c|c|c|c|c|c|c|}
\hline & Age & Gender & MS & $\mathrm{CCM}$ & SES & $\mathrm{GH}$ & PF & $\mathrm{RP}$ & RE & SF & $\mathrm{BP}$ & $\mathrm{ME}$ & VT \\
\hline & 1 & .075 & .055 & -.044 & .171 & .167 & .074 & .074 & .071 & -.028 & .096 & .027 & .151 \\
\hline \multirow[t]{2}{*}{ Age } & & .461 & .587 & .664 & .089 & .097 & .463 & .462 & .481 & .784 & .340 & .789 & .133 \\
\hline & & 1 & -.084 & .086 & .112 & .001 & -.111 & -.102 & -.074 & -.019 & -.046 & -.021 & .017 \\
\hline \multirow[t]{2}{*}{ Gender } & & & .404 & .394 & .268 & .994 & .272 & .314 & .462 & .849 & .647 & .832 & .868 \\
\hline & & & 1 & .062 & .049 & -.085 & -.069 & -.100 & -.048 & -.001 & -.076 & -.070 & -.099 \\
\hline \multirow[t]{2}{*}{ MS } & & & & .541 & .629 & .400 & .492 & .323 & .635 & .994 & .452 & .487 & .329 \\
\hline & & & & 1 & .064 & $.720^{* * *}$ & $.869^{* *}$ & $.814^{* *}$ & $.741^{* *}$ & $.448^{* *}$ & $.576^{* *}$ & $.609^{* *}$ & $.721^{* *}$ \\
\hline \multirow[t]{2}{*}{$\mathrm{CCM}$} & & & & & .530 & .000 & .000 & .000 & .000 & .000 & .000 & .000 & .000 \\
\hline & & & & & 1 & $.341^{* *}$ & .165 & .174 & $.332^{* *}$ & $.558^{* *}$ & $.379^{* *}$ & $.436^{* *}$ & $.341^{* *}$ \\
\hline \multirow[t]{2}{*}{ SES } & & & & & & .001 & .101 & .083 & .001 & .000 & .000 & .000 & .001 \\
\hline & & & & & & 1 & $.732^{* *}$ & $.798^{* *}$ & $.871^{* *}$ & $.689^{* *}$ & $.763^{* *}$ & $.829^{* *}$ & $.988^{* *}$ \\
\hline \multirow[t]{2}{*}{$\mathrm{GH}$} & & & & & & & .000 & .000 & .000 & .000 & .000 & .000 & .000 \\
\hline & & & & & & & 1 & $.889^{* *}$ & $.820^{* *}$ & $.573^{* *}$ & $.624^{* *}$ & $.670^{* *}$ & $.739^{* *}$ \\
\hline \multirow[t]{2}{*}{ PF } & & & & & & & & .000 & .000 & .000 & .000 & .000 & .000 \\
\hline & & & & & & & & 1 & $.869^{* *}$ & $.583^{* *}$ & $.650^{* *}$ & $.722^{* *}$ & $.804^{* *}$ \\
\hline \multirow[t]{2}{*}{ RP } & & & & & & & & & .000 & .000 & .000 & .000 & .000 \\
\hline & & & & & & & & & 1 & $.705^{* *}$ & $.734^{* *}$ & $.801^{* *}$ & $.874^{* *}$ \\
\hline \multirow[t]{2}{*}{ RE } & & & & & & & & & & .000 & .000 & .000 & .000 \\
\hline & & & & & & & & & & 1 & $.627^{* *}$ & $.731^{* *}$ & $.686^{* *}$ \\
\hline \multirow[t]{2}{*}{ SF } & & & & & & & & & & & .000 & .000 & .000 \\
\hline & & & & & & & & & & & 1 & $.740^{* * *}$ & $.770^{* *}$ \\
\hline \multirow[t]{2}{*}{$\mathrm{BP}$} & & & & & & & & & & & & .000 & .000 \\
\hline & & & & & & & & & & & & 1 & $.832^{* *}$ \\
\hline ME & & & & & & & & & & & & & .000 \\
\hline
\end{tabular}

CCM-clinical characteristics of morbidity, MS-marital status, SES-socioeconomic status, GH- general health perceptions, PF-physical functioning, RP -role limitations due to physical health problems, RE- role limitation due to emotional problems, SF-social functioning, BP-bodily pain, ME- mental health, and VT- vitality. Correlation is significant at $0.05 \alpha$ level, critical $r_{0.05,100}=0.1946$.

One way analysis of variance conducted to determine differences in HRQoL across classes of SES indicated significant difference across classes of SES in all domains of HRQoL. These significant differences was however found to exist between patients from low and middle socioeconomic classes, between patients from low and high socioeconomic classes and between patients from middle and high socioeconomic classes as shown in table 4 . This may imply that high socioeconomic class might be 
associated with better HRQoL than middle and low socioeconomic classes, and low socioeconomic class might be associated with having poorer HRQoL than middle socioeconomic class in patients with SCI.

From the Table 5, Turkey's honesty significant difference test was conducted to determine the difference in variation in HRQoL across classes of SES of the respondents. Statistically significant differences were found in all the pair wise of mean difference except PF. This indicates that the entire pair wise mean had variable and thus, differences in SES significantly influence HRQoL of the respondents.

Table 4

ANOVA summary table for differences in HRQoL domains across classes of SES.

\begin{tabular}{|c|c|c|c|c|c|c|}
\hline & & Sum of Squares & $\mathrm{df}$ & Mean Square & $\mathrm{F}$ & $\mathrm{p}$ \\
\hline \multirow[t]{3}{*}{$\mathrm{GH}$} & Between Groups & 2898.273 & 2 & 1449.136 & 7.449 & .001 \\
\hline & Within Groups & 18870.477 & 97 & 194.541 & & \\
\hline & Total & 21768.750 & 99 & & & \\
\hline \multirow[t]{3}{*}{ PF } & Between Groups & 1952.455 & 2 & 976.227 & 2.136 & .124 \\
\hline & Within Groups & 44322.295 & 97 & 456.931 & & \\
\hline & Total & 46274.750 & 99 & & & \\
\hline \multirow[t]{3}{*}{$\mathrm{RP}$} & Between Groups & 2543.023 & 2 & 1271.511 & 4.222 & .017 \\
\hline & Within Groups & 29211.727 & 97 & 301.152 & & \\
\hline & Total & 31754.750 & 99 & & & \\
\hline \multirow[t]{3}{*}{ RE } & Between Groups & 3236.364 & 2 & 1618.182 & 8.155 & .001 \\
\hline & Within Groups & 19247.636 & 97 & 198.429 & & \\
\hline & Total & 22484.000 & 99 & & & \\
\hline \multirow[t]{3}{*}{ SF } & Between Groups & 7064.091 & 2 & 3532.045 & 23.778 & .000 \\
\hline & Within Groups & 14408.659 & 97 & 148.543 & & \\
\hline & Total & 21472.750 & 99 & & & \\
\hline \multirow[t]{3}{*}{$\mathrm{BP}$} & Between Groups & 3853.095 & 2 & 1926.547 & 8.392 & .000 \\
\hline & Within Groups & 22269.095 & 97 & 229.578 & & \\
\hline & Total & 26122.190 & 99 & & & \\
\hline \multirow[t]{3}{*}{ ME } & Between Groups & 4166.818 & 2 & 2083.409 & 13.521 & .000 \\
\hline & Within Groups & 14945.932 & 97 & 154.082 & & \\
\hline & Total & 19112.750 & 99 & & & \\
\hline \multirow[t]{3}{*}{ VT } & Between Groups & 3044.455 & 2 & 1522.227 & 7.154 & .001 \\
\hline & Within Groups & 20638.295 & 97 & 212.766 & & \\
\hline & Total & 23682.750 & 99 & & & \\
\hline
\end{tabular}

$\mathrm{SES}=$ socioeconomic status, GH- general health perceptions, PF-physical functioning, RP -role limitations due to physical health problems, RE- role limitation due to emotional problems, SF-social functioning, BP-bodily pain, ME- mental health, and VT- vitality. Critical $F_{2,97=3.15}$ for socioeconomic status categories 
Table 5

ANOVA summary table for differences in HRQoL domains across classes of SES.

\begin{tabular}{|c|c|c|c|c|c|}
\hline Dependent Variables & (I) Anova & (J) Anova & Mean Difference (I-J) & Std. Error & $\mathrm{P}$ \\
\hline \multirow[t]{5}{*}{$\mathrm{GH}$} & Low & High & $-14.55000^{*}$ & 4.18434 & .002 \\
\hline & \multirow[t]{2}{*}{ Middle } & Low & $11.16364^{*}$ & 3.36433 & .004 \\
\hline & & High & -3.38636 & 3.64200 & .623 \\
\hline & \multirow[t]{2}{*}{ High } & Low & $14.55000^{*}$ & 4.18434 & .002 \\
\hline & & Middle & 3.38636 & 3.64200 & .623 \\
\hline \multirow[t]{6}{*}{ PF } & \multirow[t]{2}{*}{ Low } & Middle & -10.29091 & 5.15607 & .119 \\
\hline & & High & -9.95000 & 6.41278 & .272 \\
\hline & \multirow[t]{2}{*}{ Middle } & Low & 10.29091 & 5.15607 & .119 \\
\hline & & High & .34091 & 5.58161 & .998 \\
\hline & \multirow[t]{2}{*}{ High } & Low & 9.95000 & 6.41278 & .272 \\
\hline & & Middle & -.34091 & 5.58161 & .998 \\
\hline \multirow[t]{6}{*}{ RP } & \multirow[t]{2}{*}{ Low } & Middle & $-12.16364^{*}$ & 4.18588 & .013 \\
\hline & & High & -8.30000 & 5.20612 & .253 \\
\hline & \multirow[t]{2}{*}{ Middle } & Low & $12.16364^{*}$ & 4.18588 & .013 \\
\hline & & High & 3.86364 & 4.53134 & .671 \\
\hline & \multirow[t]{2}{*}{ High } & Low & 8.30000 & 5.20612 & .253 \\
\hline & & Middle & -3.86364 & 4.53134 & .671 \\
\hline \multirow[t]{6}{*}{ RE } & \multirow[t]{2}{*}{ Low } & Middle & $-12.65455^{*}$ & 3.39779 & .001 \\
\hline & & High & $-14.20000^{*}$ & 4.22595 & .003 \\
\hline & \multirow[t]{2}{*}{ Middle } & Low & $12.65455^{*}$ & 3.39779 & .001 \\
\hline & & High & -1.54545 & 3.67822 & .907 \\
\hline & \multirow[t]{2}{*}{ High } & Low & $14.20000^{*}$ & 4.22595 & .003 \\
\hline & & Middle & 1.54545 & 3.67822 & .907 \\
\hline \multirow[t]{6}{*}{ SF } & \multirow[t]{2}{*}{ Low } & Middle & $-15.92727^{*}$ & 2.93981 & .000 \\
\hline & & High & $-23.95000^{*}$ & 3.65635 & .000 \\
\hline & \multirow[t]{2}{*}{ Middle } & Low & $15.92727^{*}$ & 2.93981 & .000 \\
\hline & & High & $-8.02273^{*}$ & 3.18244 & .035 \\
\hline & \multirow[t]{2}{*}{ High } & Low & $23.95000^{*}$ & 3.65635 & .000 \\
\hline & & Middle & $8.02273^{*}$ & 3.18244 & .035 \\
\hline \multirow[t]{6}{*}{ BP } & \multirow[t]{2}{*}{ Low } & Middle & $-11.09091^{*}$ & 3.65476 & .009 \\
\hline & & High & $-18.05000^{*}$ & 4.54555 & .000 \\
\hline & \multirow[t]{2}{*}{ Middle } & Low & $11.09091^{*}$ & 3.65476 & .009 \\
\hline & & High & -6.95909 & 3.95640 & .189 \\
\hline & High & Low & $18.05000^{*}$ & 4.54555 & .000 \\
\hline & & Middle & 6.95909 & 3.95640 & .189 \\
\hline ME & Low & Middle & $-13.38182^{*}$ & 2.99412 & .000 \\
\hline & & High & $-17.45000^{*}$ & 3.72389 & .000 \\
\hline & Middle & Low & $13.38182^{*}$ & 2.99412 & .000 \\
\hline & & High & -4.06818 & 3.24123 & .424 \\
\hline & High & Low & $17.45000^{*}$ & 3.72389 & .000 \\
\hline & & Middle & 4.06818 & 3.24123 & .424 \\
\hline VT & Low & Middle & $-11.09091^{*}$ & 3.51840 & .006 \\
\hline & & High & $-15.25000^{*}$ & 4.37595 & .002 \\
\hline & Middle & Low & $11.09091^{*}$ & 3.51840 & .006 \\
\hline & & High & -4.15909 & 3.80878 & .521 \\
\hline & High & Low & $15.25000^{*}$ & 4.37595 & .002 \\
\hline & & Middle & 4.15909 & 3.80878 & .521 \\
\hline
\end{tabular}

\section{Discussion}

This study was conducted to examine the relationships between health related quality of life and socio-demographic variables among patients with SCI. It was observed that only CCM and SES had significant association with HRQoL. Sociodemographic factors like age, gender and marital status had associations with HRQoL but such associations were not significant. While gender and MS were negatively related to HRQoL, SES, 
CCMand age were found to show positive relationship with HRQoL.

The outcome of this study shows a positive and significant influence of SES and CCM on HRQoL, and specifically indicating that low SES is associated with poor HRQoL as earlier being reported in previous studies elsewhere. This finding agrees with the study of Blanes et al. 2009, Fekete et al. (2014) which concluded that a higher financial capacity of patients with SCI creates more favorable conditions and provides for a better QoL. This could however be attributed to increased co-morbidity, complications and level of pain in patients of low socioeconomic status as well as low access to medical health care systems (Fekete et al., 2014). Also, AlJadid et al. (2004) revealed in their study that the health status and QoL of patients with SCI are affected by factors such as socioeconomic status (SES).

It has also been shown that low SES associates significantly with poor HRQoL (Von Rueden et al., 2006). Furthermore, another study reported that HRQoL differs significantly across classes of SES (Hijmans et al., 2010). This factor (high SES) plays a vital role in general wellbeing as such it is not a surprise that the individuals with better SES equally have better HRQoL. This suggests that low SES may contribute to a decline in rehabilitation outcome of SCI patients thereby resulting into poor HRQoL. This could possibly be due to reduced access to and use of medical care as well as difference in lifestyle among the low socioeconomic group.

The positive and significant relationship between CCM and HRQoL suggests that having incomplete SCI is associated with better HRQoL. Complete SCI is characterized by disabling and devastating lifestyle, and this might suggest why better HRQoL is seen in patients with incomplete SCI in this study. This finding is supported by a study reporting that chronicity is one of the significant factors that influence delays in seeking treatment and, consequently, to adversely affect HRQoL (VanServellen et al., 2002). Many studies have reported that CCM are significant correlates of HRQoL in patients with SCI (Patrick et al., 1995; Pellegrino, 2000; Sherman et al., 2007) thereby agree with the finding of this study. These similar findings might be a result of similarity in study methods including population characteristics, likeness in measuring instruments of HRQoL and so on.

Marital status was found in this study to have positive correlation with HRQoL though such was insignificant, implying that being married would result into a better HRQoL. Being married suggests care and support from spouses. There is continuous support and care for each other and such a support might include reminding the spouse of ingestion of medication at the right time, support in settling hospital bill, remainder on activity to be carried out and those to be avoided; all these would go a long way improving the HRQoL. Previous studies have reported similar findings suggesting marital status influencing HRQoL in SCI patients (McColl et al., 1999; Putzke et al., 2001; Erosa et al., 2014).

The insignificant but proportionate relationship between age and HRQoL suggests that as the age increases, the HRQoL also increases and vice versa among SCI patients. This is contrary to the reports of other studies elsewhere. For example, according to Fekete et al. (2014), appears to negatively affect QoL by deteriorating the level of health, because of multiple co-morbidities in the elderly, increasing fatigue and disability. Despite the fact that most studies reported that women with SCI exhibit a lack of vitality and vigor, and have a higher proportion of medical, social and psychological problems (Westgren \& Levi, 1998), whereas the present study only establishes an insignificant and disproportionate association between gender and HRQoL except GH and VT among patients with SCI.

\section{Strengths and Limitations}

The major strength of this study is the representativeness of the sample population. This study was carried out in the largest hospital in Southsouth Nigeria that provides health care delivery to the highest number of patients with SCI in Nigeria. 
This hospital also provides health care services to people of different religious, ethnic and social affiliations. We can boldly say that our population sample represented Southern Nigerians. One of the limitations of this study is the non-probability sampling techniques employed in recruiting the respondents for the study.

\section{Conclusion}

Although age, gender and marital status had association with HRQoL but they could not determine HRQoL in SCI patients. SES and CCM play an important role in determining HRQoL in SCI patients (i.e. SES and CCM are predictors of HRQoL in patients with SCI). The use of HRQoL measures in health care is important in understanding the effectiveness of health care intervention on patients' QoL rather than their body, without which treatment may be deemed successful despite poor psychological functioning or adjustment to illness. Therefore HRQoL measures, especially this should be incorporated into clinical practice and the results should be discussed in a multidisciplinary team approach and clinical review meeting.

\section{Recommendations}

It is therefore recommended that SES and CCM should be taken into consideration during rehabilitation. Further study should be carried out on socio-demographic correlates of HRQoL in SCI subjects using a larger sample size from different hospitals across the states of Nigeria using longitudinal method. Also more studies should be carried out using different types of research tools and outcome measures. Health related quality of life measure should be introduced into clinical practice and there is a need for the training of the clinicians/clinical staff in using and interpreting the outcome measures.

\section{References}

Blanes L, Carmagnani MI, Ferreira LM. Health-related quality of life of primary caregivers of persons with paraplegia. Spinal Cord, 2007; 45(6): 399-403.

Boakye M, Leigh BC, Skelly AC. Quality of life in person with spinal cord injury: comparisons with other populations. J Neurosurg Spine, 2012; (17): 29-37.

Chandra A, Ozturk A. In context: Quality of life issues and assessment tools as they relate to patients with chronic nonmalignant pain. Research and Perspectives on Healthcare, 2005; 83: 33-37.

Erosa NA, Berry JW, Elliott TR, Underhill AT, Fine PR. Predicting quality of life 5 years after medical discharge for traumatic spinal cord injury. Br J Health Psychol, 2014; 19(4): 688-700.

Fekete C, Wahrendorf M, Reinhardt JD, Post MWM, Siegrist J. Work stress and quality of life in persons with disabilities from four European countries: the case of spinal cord injury. Qual Life Res, 2014; 3: 1661-71.

Guttmann L. Spinal cord injuries. Comprehensive management and research. London Blackwell Scientific Publications, 1973. p. 1

Hijmans CT, Fijnvandraat K, Oosterlaan J, Heijboer H, Peters M, Grootenhius MA. Double disadvantage: A case study of health related quality of life in children with sickle cell disease. Health Quality of Life Outcome, 2010; 8: 121.

McColl MA, Arnold R, Charlifue S, Frankel H. Aging, spinal cord injury, and quality of life: structural relationships. Arch Phys Med Rehabil, 2003; 84(8): 1137-44.

Mittmann N, Hitzig SL, Catharine Craven B. Predicting health preference in chronic spinal cord injury. J Spinal Cord Med, 2014; 37(5): 548-55.

Olusi SO, Ademowore AS, Ajani B. Biochemical assessment of nutritional state of gravid of different socioeconomic classification at Westley Guild Hospital, Ilesha Nigeria. Journal of Tropical Medicine and Hygiene, 1979; 82: 8-12.

Omokhodion FO, Sanya AO. Risk factors for low back pain among office workers in Ibadan, South-West Nigeria. Occupational Medicine, 2003; 53: 287-289.

Patrick DL, Deyo RA, Atlas SJ. Assessing health-related quality of life in patients with sciatica. Spine, 1995; 20(1): 899-908.

Pellegrino ED. Decisions to withdraw life-sustaining treatment: A moral algorithm. JAMA, 2000; 290(18): 283-1067.

Pereira MEMSM, Araujo TCCFA. Coping and rehabilitation of people with spinal cord injury and their caretakers. Psico (Porto Alegre), 2006; 37(1): 37-45. 
Putzke JD, Elliott TR, Scott-Richards J. Marital Status and Adjustment 1 Year Post-Spinal-Cord-Injury. J Clin Psychol Med Sett, 2001; 8(2): 101-7.

Sherman EMS, Griffiths YS, Akdag S, Connolly MB, Slick DJ, Wiebe S. Sociodemographic correlates of health related quality of life in pediatric epilepsy. Epilepsy and Behavior, 2007; 12: 96-101.

Somers MF. Spinal cord injury: functional rehabilitation. Upper Saddle River, N.J., Prentice Hall, 2001.

Suttiwong J, Vongsirinavarat M, Chaiyawat P, Vachalathiti R. Predicting community participation after spinal cord injury in Thailand. J Rehabil Med, 2015; 47(4): 325-9.
Van-Servellen G, Chang B, Lombardi E. Acculturation, socioeconomic vulnerability, and quality of life in Spanishspeaking and bilingual Latino HIV-infected men and women. West J Nurs Res, 2002; 24: 246-263.

Von-Rueden U, Gosch A, Ramjil L, Bisegger C, Ravens-Sieberer U. Socioeconomic determinants of health related quality of life in childhood and adolescence: Result from a European study. J Epidemiol Commun Health, 2006; 60: 130-5.

Westgren N, Levi R. Quality of life and traumatic spinal cord injury. Arch Phys Med Rehabil, 1998; 79: 1433-9.

World Health Organization. International Classification of Functioning, Disability and Health. Geneva, Switzerland: WHO, 2001 